\section{Meat juice serology for Toxoplasma gondii infection in chickens}

\author{
Alice Vismarra, Carlo Mangia, Elena \\ Barilli, Franco Brindani, Cristina Bacci, \\ Laura Kramer \\ Department of Veterinary Sciences, \\ University of Parma, Parma, Italy
}

\section{Abstract}

Toxoplasma gondii is an important foodborne zoonosis. Free-range chickens are at particularly high risk of infection and are also excellent indicators of soil contamination by oocysts. In the present study, hearts of 77 freerange chickens were collected at slaughter. $T$. gondii meat juice enzyme-linked immunosorbent assay was performed with a commercial kit, following validation with positive controls, from experimentally infected chickens, and negative ones. Out of 77 samples, only 66 gave sufficient meat juice for serology. Of these, 24 (36.4\%) were positive for $T$. gondii considering the $5^{*}$ standard deviation values (calculated on the optical density of negative controls), while all the samples were negative considering sample/positive\% values. Parasite-specific polymerase chain reaction was carried out on all samples obtained from heart tissue and none were positive for the presence of $T$. gondii DNA. Results would suggest that further study on the use of meat juice with a validated serological test to detect $T$. gondii in chickens could lead to widespread epidemiological studies in this important intermediate host. However, sample collection and test specificity require further evaluation.

\section{Introduction}

Toxoplasma gondii is an Apicomplexan protozoa that is considered as one of the most important food-borne parasitic zoonoses globally (Tenter et al., 2000; McAllister, 2005; Hill and Dubey, 2013). Human infection is acquired through the ingestion of infective oocysts shed by cats, which contaminate the environment, or tissue cysts present in raw or undercooked meat of the many intermediate hosts of the parasite (Dubey, 2010). Birds, including chicken, play an important role in the epidemiology of $T$. gondii. While raw or undercooked chicken meat as a source of infection for humans is less likely compared to other meats, chickens are an important source of infection for cats that in turn shed oocysts into the environment. Furthermore, free-range chickens are an excellent indicator of soil contamination in that they feed from the ground (Dubey et al., 2015).

Several serological tests can be used to determine $T$. gondii infection in poultry (Dubey et al., 1993, 2002; Casartelli-Alves et al., 2014), including the modified agglutination test (MAT), indirect immunofluorence antibody test (IFAT) and enzyme-linked immunosorbent assays (ELISA). Meat juice serology (MJS) has proven to be an excellent method for detection of $T$. gondii infection at slaughter in different species, including sheep and pigs, and has been confirmed to correlate well with serum serology (Basso et al., 2013; Meemken et al., 2014; Bacci et al., 2015). The application of meat juice serology would be ideal for large-scale investigations of $T$. gondii prevalence in poultry.

Thus, the aim of the present study was to determine seroprevalence for $T$. gondii with meat juice ELISA obtained from free-range chickens using a commercially available diagnostic kit, and to confirm the presence of the parasite with application of molecular biology techniques. Therefore a 200 - to 300 fold repetitive fragment ( $529 \mathrm{bp)}$ ) and a 35 -fold repetitive target (B1) for amplification were used.

\section{Materials and Methods}

\section{Animals}

From April to July 2015, a total of 77 chickens were sampled: forty chickens came from a backyard farm located in the Piacenza province (northern Italy), while 37 came from a large scale industrial farm with strict biosecurity measures located in Teramo province (central Italy). All animals were raised according to free-range standards, including outdoor access for a minimum of 8 hours a day and slaughter at a minimum of 54 days. The slaughterhouses were located near the poultry farms. Hearts (medium weight around 4-5 g) of 77 animals were collected, put individually in small bags, and immediately frozen at $-20^{\circ} \mathrm{C}$ for $18-24$ hours after slaughter. After thawing, meat juice was obtained for use in serology and each heart was conserved for molecular biology, according to Bacci et al. (2015).

\section{Kit validation}

A commercial ELISA test kit (ID SCREEN ${ }^{\circledR}$ Toxoplasmosis Indirect Multi-Species; IDvet, Grabels, France) was used. However, since this kit has been developed for detection of anti- $T$. gondii immunoglobulin $\mathrm{G}(\operatorname{IgG})$ antibodies in pigs, cats, ruminants and dogs, some adaptations were made for the diagnosis in chickens. Briefly, the conjugate of the kit was replaced with anti-chicken IgG (whole molecule) peroxidase conjugate (Sigma Aldrich ${ }^{\circledR}$, St. Louis,
Correspondence: Cristina Bacci, Department of Veterinary Sciences, University of Parma, via del Taglio 10, 43126 Parma, Italy.

Tel: +39.0521.032740.

E-mail: cristina.bacci@unipr.it

Key words: Toxoplasma gondii; Serology; Meat juice; ELISA.

Conflict of interest: the authors declare no potential conflict of interest.

Acknowledgements: the authors thank Dr. Damer Blake for excellent supervision of AV during her $\mathrm{PhD}$ training.

Received for publication: 14 October 2015. Revision received: 18 November 2015. Accepted for publication: 18 November 2015.

This work is licensed under a Creative Commons Attribution-NonCommercial 4.0 International License (CC BY-NC 4.0).

(C) Copyright A. Vismarra et al., 2016

Licensee PAGEPress, Italy

Italian Journal of Food Safety 2016; 5:5586

doi:10.4081/ijfs.2016.5586

MO, USA) and tested with positive control serum obtained from experimentally-infected chickens and negative uninfected controls (kindly provided by Dr. B. Bangoura, University of Leipzig, Germany). In order to define the best conditions for testing meat juice samples, positive controls were tested at different dilutions (1:40, 1:80, 1:160, 1:320). Negative controls were tested in toto. For each condition, the secondary antibody was used at three different concentrations $(1: 15,000,1: 20,000$, 1:30,000). The highest optical density (OD) values for negative controls were considered as plate cut-off. We also modified the incubation temperature to $37^{\circ} \mathrm{C}$, according to Sun et al. (2015). Plates were incubated for $1 \mathrm{~h}$ with serum samples and then for 45 min with the secondary antibody. All other conditions were met according to manufacturer's instructions. Optical densities were read at $450 \mathrm{~nm}$ with a spectrophotometer (Multiskan ${ }^{\mathrm{TM}}$ FC Microplate Photometer; Thermo Scientific, Swedesboro, NJ, USA) and results were expressed in two ways: i) as sample/positive (S/P)\% values $\left[\mathrm{S} / \mathrm{P} \%=\left(\mathrm{OD}_{\text {sample }}-\mathrm{OD}_{\text {negative controls }}\right) /\left(\mathrm{OD}_{\text {positive con- }}\right.\right.$ trols $-0 D_{\text {negative control }} \times 100$ ] greater than $50 \%$ (samples with $\mathrm{S} / \mathrm{P} \% \leq 40 \%$ were considered negative, between 40 and $50 \%$ were considered doubtful); ii) as $5 \times$ the mean standard deviation (SD) of the mean of negative controls $\left(5^{*} \mathrm{SD}\right)$. All the samples that presented an OD value higher than the value $5^{*} \mathrm{SD}$ were considered positive (Dubey et al., 2005). 


\section{Meat juice serology}

All collected meat juice samples were tested in toto, according to conditions described above. Based on results of kit validation, secondary antibody was used at a dilution of 1:15,000. Positive serum controls were tested at a 1:40 dilution.

\section{DNA extraction and Toxoplasma gondii identification with} polymerase chain reaction

Hearts from all slaughtered chickens were sectioned and homogenised for DNA extraction. Briefly, hearts were surface-sterilised by submersion in $70 \%$ ethanol. All the cardiac muscle, cleaned from fat and connective tissue, was sampled and blended with the addition of $50 \mathrm{~mL}$ of phosphate buffered saline (PBS). Two-hundred $\mu \mathrm{L}$ of tissue were used for the DNA extraction carried out using a commercial kit (DNeasy Blood \& Tissue Kit; Qiagen, Valencia, CA, USA).

Toxoplasma gondii presence was confirmed by a PCR targeting a 529 bp region, using the primers T0X4 and TOX5, as described by Homan et al. (2000). Amplification was performed by 2 min incubation at $94^{\circ} \mathrm{C}$ followed by 35 cycles of $1 \mathrm{~min}$ at $94^{\circ} \mathrm{C}, 1 \mathrm{~min}$ at $55^{\circ} \mathrm{C}, 1 \mathrm{~min}$ at $72^{\circ} \mathrm{C}$ and a final $10 \mathrm{~min}$ incubation at $72^{\circ} \mathrm{C}$. A second nested-PCR protocol, to confirm or not the presence of $T$. gondii, was performed essentially as described by Burg et al. (1989) using the internal and external primers amplifying the $B 1$ gene. The first round amplification was performed in a final volume of $25 \mu \mathrm{L}$, with $0.1 \mu \mathrm{M}$ each primer, and $2 \times$ reaction mixture (MyTaqmix-ready-to-use; Bioline, Taunton, MA, USA). The amplification protocol foresaw a first denaturation step at $94^{\circ} \mathrm{C}$ for 2 min, followed by 40 cycles of $94^{\circ} \mathrm{C}$ for $10 \mathrm{sec}$, $57^{\circ} \mathrm{C}$ for $10 \mathrm{sec}, 72^{\circ} \mathrm{C}$ for $30 \mathrm{sec}$. The nested amplification contained $1 \mu \mathrm{L}$ of first-round product, $0.5 \mu \mathrm{M}$ of each primer in a final volume of $25 \mu \mathrm{L}$. Nested reaction consisted of 40 cycles (after a first denaturation at $94^{\circ} \mathrm{C}$ for 2

Table 1. Results of enzyme-linked immunosorbent assay (meat juice) and polymerase chain reaction (heart) on the samples in the two farms.

\begin{tabular}{|c|c|c|c|c|c|c|c|c|c|}
\hline \multirow{2}{*}{$\begin{array}{l}\text { Sample } \\
\text { farm Piacenza }\end{array}$} & \multirow[t]{2}{*}{ PCR } & \multicolumn{2}{|c|}{ ELISA } & \multirow[t]{2}{*}{ OD value } & \multirow{2}{*}{$\begin{array}{c}\text { Sample } \\
\text { farm Teramo }\end{array}$} & \multirow[t]{2}{*}{ PCR } & \multicolumn{2}{|c|}{ ELISA } & \multirow[t]{2}{*}{ OD value } \\
\hline & & $\mathrm{S} / \mathrm{P} \%$ & $5 * S D$ & & & & $\mathrm{~S} / \mathrm{P} \%$ & $5 * S D$ & \\
\hline 1 & - & - & + & 0.1387 & 2 & - & - & - & 0.0489 \\
\hline 2 & - & - & + & 0.0710 & 4 & - & - & - & 0.0474 \\
\hline 3 & - & - & + & 0.0720 & 5 & - & - & - & 0.0513 \\
\hline 5 & - & - & + & 0.0772 & 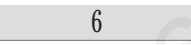 & - & - & - & 0.0498 \\
\hline 6 & - & - & + & 0.1107 & $\sqrt{2}$ & - & - & - & 0.0515 \\
\hline 8 & - & - & + & 0.1886 & 9 & - & - & + & 0.0740 \\
\hline 11 & - & - & + & 0.0838 & 10 & - & - & - & 0.0529 \\
\hline 12 & - & - & + & 0.0854 & 11 & - & - & - & 0.0484 \\
\hline 13 & - & - & + & 0.0668 & 12 & - & - & - & 0.0487 \\
\hline 14 & - & - & + & 0.0625 & 13 & - & - & - & 0.0469 \\
\hline 15 & - & - & + & 0.1113 & 14 & - & - & - & 0.0519 \\
\hline 17 & - & - & + & 0.0643 & 15 & - & - & - & 0,0495 \\
\hline 18 & - & - & - & 0.0577 & 17 & - & - & - & 0.0503 \\
\hline 19 & - & - & + & 0.0769 & 19 & - & - & - & 0.0522 \\
\hline 20 & - & - & + & 0.0881 & 20 & - & - & - & 0.0513 \\
\hline 21 & - & - & + & 0.0636 & 21 & - & - & - & 0.0483 \\
\hline 22 & - & - & - & 0.0580 & 23 & - & - & - & 0.0500 \\
\hline 23 & - & - & - & 0.0586 & 24 & - & - & - & 0.0563 \\
\hline 24 & - & - & - & 0.0576 & 25 & - & - & - & 0.0542 \\
\hline 25 & - & - & + & 0.1024 & 26 & - & - & - & 0.0518 \\
\hline 26 & - & - & + & 0.1203 & 27 & - & - & - & 0.0570 \\
\hline 27 & - & - & + & 0.0671 & 28 & - & - & - & 0.0520 \\
\hline 28 & - & - & + & 0.0632 & 29 & - & - & - & 0.0500 \\
\hline 29 & - & - & - & 0.0585 & 30 & - & - & - & 0.0500 \\
\hline 30 & - & - & - & 0.0588 & 31 & - & - & + & 0.0631 \\
\hline 31 & - & - & - & 0.0556 & 32 & - & - & - & 0.0496 \\
\hline 32 & - & - & - & 0.0562 & 33 & - & - & - & 0.0500 \\
\hline 33 & - & - & - & 0.0573 & 34 & - & - & - & 0.0519 \\
\hline 34 & - & - & - & 0.0554 & 35 & - & - & - & 0.0497 \\
\hline 35 & - & - & + & 0.0742 & 36 & - & - & - & 0.0524 \\
\hline 36 & - & - & + & 0.0850 & 37 & - & - & - & 0.0597 \\
\hline 37 & - & - & + & 0.1370 & & & & & \\
\hline 38 & - & - & - & 0.0556 & & & & & \\
\hline 39 & - & - & - & 0.0517 & & & & & \\
\hline 40 & - & - & - & 0.0574 & & & & & \\
\hline
\end{tabular}


min) of $94^{\circ} \mathrm{C}$ for $10 \mathrm{sec}$, annealing at $62.5^{\circ} \mathrm{C}$ for $10 \mathrm{sec}, 72^{\circ} \mathrm{C}$ for $15 \mathrm{sec}$. Negative controls from first round amplification and an additional second round negative control of sterile water were included in the nested reactions. Positive controls were included in each PCR reaction.

The PCR products were fractionated on a $1.5 \%$ agarose gel, stained with SybrSafe (Life technologies) and visualized by UV transillumination; the weight of the bands were identified using a marker of molecular weight (100 bp DNA ladder; Promega, Madison, WI, USA).

\section{Results}

Of the 77 hearts collected, only 66 gave sufficient meat juice for use in ELISA. Table 1 shows the results of meat juice serology. None of the meat juice samples (0\%) were positive when considering S/P\% values, while 24 (36.4\%) were positive if OD values were expressed as $5^{*} \mathrm{SD}$ values (positive cut-off 0.062 ). None of the samples was positive for the presence of $T$. gondii DNA following PCR with two parasite-specific primers.

\section{Discussion}

A recent review has reported that prevalence of $T$. gondii in free-range chickens can be as high as 100\% (Dubey, 2010), confirming their role in the epidemiology of infection and the related zoonotic risk through consumption of undercooked chicken meat.

Serum serology for T. gondii in chickens can be carried out with different methods, including MAT, IFAT and ELISA. Sensitivity and specificity vary and depend on different factors, including age, number of animals sampled, and test used. Currently, there are no available ELISA tests for T. gondii serology in chickens. However, Casartelli-Alves et al. (2014) recently reported sensitivity and specificity of 85 and $56 \%$ respectively, in naturally exposed chickens, using a commercial ELISA adapted to chicken sera. Meat juice serology (MJS) is increasingly used to determine the prevalence of various pathogens in different animal species, including $T$. gondii infection in pigs and sheep (Lundèn et al., 2002; Berger-Schoch et al., 2011; Glor et al., 2013; Bacci et al., 2015). There are currently no reports on the use of MJS for T. gondii infection in chickens at slaughter. Dubey et al. (2005) applied the ELISA technique to evaluate the presence of anti-T. gondii antibodies in tissue fluid obtained from retail breast meat, reporting a prevalence of $1.3 \%$. In the present study, hearts were used for obtaining meat juice. A recent study has shown that comparison of $T$. gondiispecific antibody titers in meat juice and serum of pigs revealed a strong positive correlation for meat juice from heart tissue, making this the organ of choice for MJS (Wallander $e t$ al., 2015). The commercial kit used in the present survey has been validated for multiple species, but not for chickens, and the protocol was adapted by changing the species-specific conjugate and testing performance with serum from experimentally infected chickens. Serum from experimentally infected chickens was used both in toto for kit validation and at a 1:40 dilution when testing meat juice samples in order to decrease antibody concentration and to better mimic OD values in meat juice, which are consistently lower compared to serum (Wallander et al., 2015). Positive titers in meat juice collected from the hearts were established in two different ways, according to manufactures' instructions and according to Dubey et al. (2005), resulting in a prevalence of approximately 0 and $36.4 \%$ respectively. The results obtained from the two evaluation methods were very different. If the positive control had a very high concentration of immunoglobulin Y, thus giving a high cut off OD value, samples from chickens with low antibody titres may have resulted negative with the $\mathrm{S} / \mathrm{P} \% \mathrm{cal}$ culation. On the other hand, five times the mean standard deviation of the mean of all samples tested may have resulted in a higher number of false positive samples. It would be necessary to further study the validation of this kit with experimentally infected birds.

Considering $5 *$ SD values, prevalence values were notably different between the two farms, probably due to different farm management. The large scale, industrial free-range chickens are kept under strict biosecurity measures, including barriers, which inhibit access by cats, thus making soil contamination by oocysts nearly impossible. The backyard farm in northern Italy, on the contrary, is family run and the grounds are open to the surrounding countryside.

Parasite-specific PCR was negative in all the samples, thus it was not possible to verify positive serology with the presence of $T$. gondii in myocardial tissue of naturally exposed, freerange chickens. Hill et al. (2006) reported similar results when comparing diagnostic methods in both $T$. gondii-experimentally and naturally infected pigs and retail pork products. The authors cited different reasons for DNA-negative samples, including limited tissue sample size and random distribution of tissue cysts. Geuthner et al. (2014) also reported a very low prevalence of $T$. gondii DNA in muscle tissue from experimentally infected chickens (2.1\%), suggesting that $T$. gondii does not persist for long periods in this species. Dubey et al. (2005) found no positive samples of retail breast meat when tissue was bioassayed in mice. The results of the present study would confirm these previous reports and would suggest that while positivity in MJS may be an indicator of infection risk, it likely does not correlate with detection in the meat.

In Italy free range farms have increased in recent years and approximately 3,500,000 chickens were raised in 2013 (www.istat.it), making Italy one of the most important producers in Europe. For its features, free-range livestock could be a source of infection of $T$. gondii and an indicator of contamination, even if studies on infection prevalence in Italian poultry are still limited.

\section{Conclusions}

To conclude, we have shown that MJS with a commercially available ELISA kit, adapted for chicken serum, can be considered as a promising tool for wide-scale epidemiological studies for T. gondii in poultry. The development of a valid ELISA test for use in slaughtered chickens would be extremely useful since the important role that chickens play in T. gondii epidemiology, in particular for the risk of zoonotic infection and food safety.

\section{References}

Bacci C, Vismarra A, Mangia C, Bonardi S, Bruini I, Genchi M, Kramer L, Brindani F, 2015. Detection of Toxoplasma gondii in free-range, organic pigs in Italy using serological and molecular methods. Int $\mathrm{J}$ Food Microbiol 202:54-6.

Basso W, Hartnack S, Pardini L, Maksimov P, Koudela B, Venturini MC, Schares G, Sidler X, Lewis FI, Deplazes P, 2013. Assessment of diagnostic accuracy of a commercial ELISA for the detection of Toxoplasma gondii infection in pigs compared with IFAT, TgSAG1-ELISA and Western blot, using a Bayesian latent class approach. Int J Parasitol 43:565-70.

Berger-Schoch AE, Bernet D, Doherr MG, Gottstein B, Frey CF, 2011. Toxoplasma gondii in Switzerland: a serosurvey based on meat juice analysis of slaughtered pigs, wild boar, sheep and cattle. Zoonoses Public Hlth 58:472-8.

Burg JL, Grover CM, Pouletty P, Boothroyd JC, 1989. Direct and sensitive detection of a pathogenic protozoan, Toxoplasma gondii, by Polymerase Chain Reaction. J Clin Microbiol 27:1787-92.

Casartelli-Alves L, Boechat VC, Macedo-Couto R, Ferreira LC, Nicolau JL, Neves LB, Millar PR, Vicente RT, Oliveira RV, Muniz AG, Bonna IC, Amendoeira MR, Silva RC, 
Langoni H, Schubach TM, Menezes RC, 2014. Sensitivity and specificity of serological tests, histopathology and immunohistochemistry for detection of Toxoplasma gondii infection in domestic chickens. Vet Parasitol 204:346-51.

Dubey JP, 2010. Toxoplasma gondii infections in chickens (Gallus domesticus): prevalence, clinical disease, diagnosis and public health significance. Zoonoses Public HIth 57:60-73.

Dubey JP, Graham DH, Blackston CR, Lehmann T, Gennari SM, Ragozo AMA, Nishi SM, Shen SK, Kwok OCH, Hill DE, Thulliez P, 2002. Biological and genetic characterization of Toxoplasma gondii isolates from chickens (Gallus domesticus) from Sao Paulo, Brazil: unexpected findings. Int $\mathrm{J}$ Parasitol 32:99-105.

Dubey JP, Hill DE, Jones JL, Hightower AW, Kirkland E, Roberts JM, Marcet PL, Lehmann T, Vianna MC, Miska K, Sreekumar C, Kwok OC, Shen SK, Gamble HR, 2005. Prevalence of viable Toxoplasma gondii in beef, chicken and pork from retail meat stores in the United States: risk assessment to consumers. J Parasitol 91:1082-93.

Dubey JP, Lehmann T, Lautner F, Kwok OC, Gamble HR, 2015. Toxoplasmosis in sentinel chickens (Gallus domesticus) in New England farms: seroconversion, distribu- tion of tissue cysts in brain, heart, and skeletal muscle by bioassay in mice and cats. Vet Parasitol 214:55-8.

Dubey JP, Ruff MD, Camargo ME, Shen SK, Wilkins GL, Kwok OC, Thulliez P, 1993. Serologic and parasitologic responses of domestic chickens after oral inoculation with Toxoplasma gondii oocysts. Am J Vet Res 54:1668-72.

Geuthner AC, Koethe M, Ludewig M, Pott S, Schares G, Daugschies A, Bangoura B, 2014. Persistence of Toxoplasma gondii tissue stages in poultry over a conventional fattening cycle. Parasitology 141:135964.

Glor SB, Edelhofer R, Grimm F, Deplazes P, Basso W, 2013. Evaluation of a commercial ELISA kit for detection of antibodies against Toxoplasma gondii in serum, plasma and meat juice from experimentally and naturally infected sheep. Parasite Vector 6:85.

Hill DE, Chirukandoth S, Dubey JP, Lunney JK, Gamble HR, 2006. Comparison of detection methods for Toxoplasma gondii in naturally and experimentally infected swine. Vet Parasitol 141:9-17.

Hill DE, Dubey JP, 2013. Toxoplasma gondii prevalence in farm animals in the United States. Int J Parasitol 43:107-13.

Homan WL, Vercammen M, De Braekeleer J, Verschueren H, 2000. Identification of a
200- to 300 -fold repetitive 529 bp DNA fragment in Toxoplasma gondii, and its use for diagnostic and quantitative PCR. Int J Parasitol 30:69-75.

Lundén A, Lind P, Engvall EO, Gustavsson K, Uggla A, Vågsholm I, 2002. Serological survey of Toxoplasma gondii infection in pigs slaughtered in Sweden. Scand J Infect Dis 34:362-5.

McAllister MM, 2005. A decade of discoveries in veterinary protozoology changes our concept of "subclinical" toxoplasmosis. Vet Parasitol 132:241-7.

Meemken D, Tangemann AH, Meermeier D, Gundlach S, Mischok D, Greiner M, Klein G, Blaha T, 2014. Establishment of serological herd profiles for zoonoses and production diseases in pigs by "meat juice multiserology". Prev Vet Med 113:589-98.

Sun X, Wang Z, Li J, Wei F, Liu Q, 2015. Evaluation of an indirect ELISA using recombinant granule antigen GRA1, GRA7 and soluble antigens for serodiagnosis of Toxoplasma gondii infection in chickens. Res Vet Sci 100:161-4.

Tenter AM, Heckeroth AR, Weiss LM, 2000. Toxoplasma gondii: from animals to humans. Int J Parasitol 30:1217-58.

Wallander C, Frössling J, Vågsholm I, Burrells A, Lundén A, 2015. "Meat juice" is not a homogeneous serological matrix. Foodborne Pathog Dis 12:280-8. 